\title{
Parathyroid hormone may play a role in the pathophysiology of primary hypertension
}

\author{
Lasse Oinonen ${ }^{1}$, Antti Tikkakoski ${ }^{1,2}$, Jenni Koskela ${ }^{1,3}$, Arttu Eräranta ${ }^{1}$, Mika Kähönen ${ }^{1,2}$, Onni Niemelä4, \\ Jukka Mustonen ${ }^{1,3}$ and Ilkka Pörsti ${ }^{1,3}$
}

${ }^{1}$ Faculty of Medicine and Health Technology, Tampere University, Tampere, Finland

2Department of Clinical Physiology, Tampere University Hospital, Tampere, Finland

${ }^{3}$ Department of Internal Medicine, Tampere University Hospital, Tampere, Finland

${ }^{4}$ Department of Laboratory Medicine and Medical Research Unit, Seinäjoki Central Hospital, Seinäjoki, Finland

Correspondence should be addressed to L Oinonen: lasse.oinonen@tuni.fi

\begin{abstract}
Parathyroid hormone has been related with the risk of hypertension, but the matter remains controversial. We examined the association of parathyroid hormone with central blood pressure and its determinants in 622 normotensive or never-treated hypertensive subjects aged 19-72 years without diabetes, cardiovascular or renal disease, or cardiovascular medications. The methods were whole-body impedance cardiography and analyses of pulse wave and heart rate variability. Cardiovascular function was examined in sex-specific tertiles of plasma parathyroid hormone (mean concentrations 3.0, 4.3 and $6.5 \mathrm{pmol} / \mathrm{L}$, respectively) during head-up tilt. Explanatory factors for haemodynamics were further investigated using linear regression analyses. Mean age was 45.0 (s.D. 11.7) years, BMI $26.8(4.4) \mathrm{kg} / \mathrm{m}^{2}$, seated office blood pressure 141/90 (21/12) $\mathrm{mmHg}$, and 309 subjects (49.7\%) were male. Only five participants had elevated plasma parathyroid hormone and calcium concentrations. Highest tertile of parathyroid hormone presented with higher supine and upright aortic diastolic blood pressure $(P<0.01)$ and augmentation index $(P<0.01)$, and higher upright systemic vascular resistance $(P<0.05)$ than the lowest tertile. The tertiles did not present with differences in pulse wave velocity, cardiac output, or measures of heart rate variability. In linear regression analyses, parathyroid hormone was an independent explanatory factor for aortic systolic $(P=0.005)$ and diastolic $(P=0.002)$ blood pressure, augmentation index $(P=0.002)$, and systemic vascular resistance $(P=0.031)$. To conclude, parathyroid hormone was directly related to central blood pressure, wave reflection, and systemic vascular resistance in subjects without cardiovascular comorbidities and medications. Thus, parathyroid hormone may play a role in the pathophysiology of primary hypertension.
\end{abstract}

\section{Introduction}

A great majority of hypertensive subjects ( 90\%) have primary hypertension with an undefined aetiology (1). Circulating parathyroid hormone (PTH) concentration has been associated with blood pressure (BP) $(2,3,4)$ and risk of hypertension in the general population (5). However, the influence of PTH on vascular function and haemodynamics remains controversial.
Receptors for PTH have been discovered in cardiomyocytes (6), vascular smooth muscle cells (7) and in the endothelial cells (8). In experimental animals acute PTH administration induces vasodilatation (9), while subacute infusion of a physiological PTH dose in healthy humans elevates BP (10). The link between chronically elevated PTH and BP remains unclear, but in the general 
population high serum PTH concentration is associated with high aldosterone levels (11), elevated aldosteroneto-renin ratio (12), impaired endothelial function (13), and arterial stiffness (14). However, contrary reports also exist (15). In primary hyperparathyroidism, whether accompanied by hyper- or normocalcemia, hypertension is detected in $40-65 \%$ of patients $(4,16)$. Structural and functional alterations in arteries $(17,18,19)$, and enhanced reactivity to the pressor factors of the sympathetic nervous system and the renin-angiotensin-aldosterone axis $(16,20,21)$, may contribute to the elevation of BP in hyperparathyroidism.

We recently found that plasma total calcium concentration was directly linked to the level of BP via elevated systemic vascular resistance (SVR) in normotensive and hypertensive subjects without antihypertensive agents (22). In the present cross-sectional study, we examined whether plasma PTH, a key regulator of calcium levels (23), is associated with central BP and its haemodynamic determinants in 622 normotensive or never-treated hypertensive subjects, who had plasma PTH and calcium concentrations predominantly within the normal range. Passive head-up tilt was included to examine haemodynamics at rest and during physiological activation of the sympathetic nervous system. To our understanding, similar comprehensive evaluations of supine and upright haemodynamics in relation to plasma PTH levels have not been performed previously.

\section{Subjects and methods}

\section{Study population}

Subjects were selected from an ongoing investigation on haemodynamics in primary and secondary hypertension (DYNAMIC study, clinical trial registration NCT01742702), currently comprising 1349 subjects. The enrolment has been previously described (22). The study was approved by the ethics committee of the Tampere University Hospital (code R06086M) and the Finnish Medicines Agency (Eudra-CT number 2006-002065-39), and it complies with the Declaration of Helsinki. Signed informed consent was obtained from all participants.

This study population comprised 309 men and 313 women aged 19-72 years after exclusion of subjects who had (i) antihypertensive or other medications with direct haemodynamic influences (such as $\alpha_{1}$-adrenoceptor blockers for prostate hyperplasia, and $\beta_{2}$-adrenoreceptor agonists for asthma), (ii) history of cardiovascular or cerebrovascular disease, (iii) heart rhythm other than sinus, (iv) diabetes mellitus, (v) chronic kidney disease (estimated glomerular filtration rate (GFR) $<60 \mathrm{~mL} /$ $\mathrm{min} / 1.73 \mathrm{~m}^{2}$, or proteinuria), (vi) chronic liver disease, (vii) secondary hypertension (24), (viii) psychiatric illness other than mild depression or anxiety, or (ix) alcohol or substance abuse. Plasma PTH and calcium concentrations were not among the exclusion criteria. Recordings were not performed to subjects having any acute illness.

Based on office BP measurements and the ESH/ESC hypertension criteria (24), 39\% of the study participants were normotensive (93 men and 151 women) and $60.4 \%$ were hypertensive ( 214 men and 158 women). In total $158(25.4 \%)$ of the participants used one or more medications (Supplementary Table 1, see section on supplementary materials given at the end of this article). Vitamin D supplements were used by 101 subjects and calcium supplements by 19 subjects. One hundred and eight women were post-menopausal.

\section{Laboratory analyses}

Blood and urine samples were collected after $\sim 12 \mathrm{~h}$ of fasting. The detailed protocol for laboratory analyses has been described previously (22). The reference range for plasma intact PTH in our laboratory is $1.6-6.9 \mathrm{pmol} / \mathrm{L}$, and for plasma total calcium $2.15-2.51 \mathrm{mmol} / \mathrm{L}$.

\section{Protocol for haemodynamic measurements}

Prior to the recordings the participants were directed to abstain from caffeine, smoking, and heavy meals for $\geq 4 \mathrm{~h}$, and from alcohol for $\geq 24 \mathrm{~h}$. Beat-to-beat supine haemodynamic data were recorded for $5 \mathrm{~min}$, followed by 5 min of passive head-up-tilt (25) according to a previously described protocol (22). The mean values of each minute during the 10-min recording were calculated for statistics. For pulse wave velocity only the supine $(0-5 \mathrm{~min})$ values were used.

\section{Pulse wave analysis}

A tonometric sensor (Colin BP-508T, Colin Medical Instruments Corp., USA) was used to record a continuous radial BP and pulse waveform, calibrated four times during the 10-min recording by contralateral brachial BP measurements. Aortic BP and pulse wave reflections were derived utilising a transfer function (SphygmoCor ${ }^{\circledR} \mathrm{PWMx}$, AtCor Medical, Australia) (26). Aortic pulse pressure, augmentation pressure, and augmentation index (AIx;

This work is licensed under a Creative Commons Attribution-NonCommercial-NoDerivatives 4.0 enternationad License.ifica. com at 04/26/2023 12:21:26PM 
aortic augmentation pressure/aortic pulse pressure $\times 100$ ) adjusted to heart rate 75 b.p.m. were determined using SphygmoCor ${ }^{\circledR}$ software.

\section{Impedance cardiography}

Whole-body impedance cardiography (CircMon ${ }^{\circledR}$, JR Medical Ltd., Estonia) was utilised to determine beat-tobeat heart rate, stroke volume, cardiac output, aortic-topopliteal pulse wave velocity (PWV), extracellular water volume (ECW), and ECW balance, as previously described $(22,27)$. SVR was calculated from tonometric BP and cardiac output: assumed normal central venous pressure ( $3 \mathrm{mmHg}$ ) was subtracted from mean arterial pressure, and the value was divided by cardiac output (27). Mean ECW balance in the lowest PTH tertile was adjusted to 1.0. The repeatability and reproducibility of the protocol have been shown $(25,28,29)$.

\section{Frequency domain analysis of heart rate variability}

Cardiac autonomic tone was evaluated using frequency domain analyses of heart rate variability (HRV) (30, 31). One-channel electrocardiograms were recorded at a sampling rate of $200 \mathrm{~Hz}$ (22). The Fast Fourier Transformation was utilised to calculate (i) power in low frequency (LF) range $(0.04-0.15 \mathrm{~Hz}$ ), (ii) power in high frequency (HF) range $(0.15-0.40 \mathrm{~Hz}$ ), and (iii) $\mathrm{LF} / \mathrm{HF}$ ratio. HF oscillations relate to parasympathetic tone, while the LF oscillations are mainly mediated by alterations in sympathetic tone but are also influenced by parasympathetic activity (32). The LF/HF ratio reflects cardiac sympathovagal balance (33).

\section{Statistical analyses}

The subjects were stratified into PTH tertiles within each sex, and one-way ANOVA was applied to assess differences between the tertiles. Haemodynamics in the PTH tertiles were compared using multivariable ANOVA (MANOVA) for repeated measures, with adjustments for the demographic, clinical and biochemical variables that presented with significant differences between the tertiles. The Bonferroni correction was applied in post hoc analyses and Levene's test was used to test the homogeneity of variances. Pearson's $\left(r_{p}\right)$ and Spearman's $\left(r_{s}\right)$ correlations were calculated, as appropriate.

Multivariable linear regression analyses with backward elimination were used to investigate the explanatory factors for the haemodynamic variables. The selection criterium for potential explanatory variables was that they correlated significantly $(P<0.05)$ with aortic systolic BP, diastolic BP, or PTH. The skewed distributions of PTH, 25-hydroxyvitamin $\mathrm{D}_{3}\left(25(\mathrm{OH})_{2} \mathrm{D}_{3}\right)$, C-reactive protein (CRP), triglycerides, alkaline phosphatase (ALP), alanine aminotransferase (ALT), renin, aldosterone, alcohol consumption, and dairy product consumption were $\operatorname{Lg}_{10}$-transformed. Smoking status was categorised to current smokers, previous smokers or never smokers using two discrete variables. The final model included age, sex, BMI, cystatin C derived estimated GFR (34), ECW balance, smoking status, vitamin D supplement use; plasma concentrations of natrium, calcium, phosphate, uric acid, low-density lipoprotein (LDL) cholesterol, high-density lipoprotein (HDL) cholesterol, glucose, and insulin; $\mathrm{Lg}_{10}$ of plasma CRP, $\mathrm{PTH}, 25(\mathrm{OH})_{2} \mathrm{D}_{3}$, ALP, ALT, triglycerides, renin, and aldosterone; and $\operatorname{Lg}_{10}$ of alcohol and dairy product consumption. Additionally, PWV was included in the regression models for aortic systolic BP, diastolic BP, and AIx.

SPSS version 26.0 (IBM SPSS) was used for statistics. The results were presented as means, and S.D., S.E., or 95\% CI of the mean. $P<0.05$ was considered statistically significant.

\section{Results}

\section{Study population}

The total study population comprised 622 subjects and $49.7 \%$ were men. Mean age was 45.0 (s.D. 11.7) years, BMI 26.8 (s.D. 4.4) $\mathrm{kg} / \mathrm{m}^{2}$, and seated office BP $141 / 90$ (s.D. 21/12) $\mathrm{mmHg}$. The clinical characteristics in sex-adjusted tertiles of plasma PTH are presented in Table 1. Altogether 143 of the participants (23\%) were obese (BMI $>30 \mathrm{~kg} / \mathrm{m}^{2}$ ), 243 (39\%) were overweight (BMI 25.1-30 kg/m²), while $236(38 \%)$ had BMI $\leq 25 \mathrm{~kg} / \mathrm{m}^{2}$. Age and BMI were higher in PTH tertiles 2 and 3 vs tertile 1 . A significant correlation was observed between PTH and BMI in the obese participants $\left(\mathrm{r}_{\mathrm{S}}=0.247, P=0.003\right)$, in the overweight participants $\left(\mathrm{r}_{\mathrm{S}}=0.152, P<0.017\right)$, but not in subjects with $\mathrm{BMI} \leq 25 \mathrm{~kg} / \mathrm{m}^{2}\left(\mathrm{r}_{\mathrm{S}}=0.087, P=0.182\right)$. Dairy product consumption was lower in PTH tertile 3 vs tertile 1 . There were no differences in volume homeostasis (ECW and ECW balance), proportion of current smokers, alcohol consumption, or proportion of vitamin D or calcium supplement users between the PTH tertiles. Mean seated office BP, mean supine brachial BP (both measured with auscultatory method), and mean supine radial $\mathrm{BP}$ (measured with applanation tonometry) were higher in PTH tertiles 2 and 3 than in tertile 1. 
Table 1 Demographics, clinical characteristics and laboratory results in tertiles of plasma parathyroid hormone concentration adjusted for sex.

\begin{tabular}{l}
\hline Demographics and clinical characteristics \\
\hline Males (\%) \\
Age (years) \\
BMI (kg/m²) \\
Extracellular water volume (L) \\
Extracellular water balance \\
Current smokers (\%) \\
Alcohol consumption (standard drinks/week) \\
Dairy product consumption (standard dose/day) \\
Calcium supplement users (\%) \\
Vitamin D supplement users (\%) \\
Seated brachial office blood pressure measured by \\
physician (mmHg) \\
Supine brachial blood pressure measured by \\
nurse (mmHg) \\
Supine radial laboratory blood pressure (mmHg)
\end{tabular}

\begin{tabular}{c}
\hline PTH tertile 1 $(n=206)$ \\
\hline 49.5 \\
$42.3(12.7)$ \\
$25.4(3.9)$ \\
$12.9(1.9)$ \\
$1.00(0.12)$ \\
15.5 \\
$5.0(6.6)$ \\
$3.5(2.3)$ \\
1.9 \\
18.9 \\
$136(21) / 86(11)$ \\
$127(17) / 78(11)$ \\
$127(19) / 72(12)$
\end{tabular}

\begin{tabular}{c}
\hline PTH tertile $\mathbf{2}(n=208)$ \\
\hline 50 \\
$45.8(10.8)^{\mathrm{a}}$ \\
$27.1(4.1)^{\mathrm{a}}$ \\
$12.9(1.8)$ \\
$0.99(0.10)$ \\
12 \\
$4.5(5.3)$ \\
$3.1(2.0)$ \\
3.8 \\
15.9 \\
$143(20)^{\mathrm{a}} / 90(12)^{\mathrm{a}}$ \\
$134(18)^{\mathrm{a} / 81}(12)^{\mathrm{a}}$ \\
$132(19)^{\mathrm{a}} / 76(12)^{\mathrm{a}}$ \\
\hline
\end{tabular}

PTH tertile $\mathbf{3}(n=208)$
49.5
$47.0(11.2)^{\mathrm{a}}$
$27.9(4.7)^{\mathrm{a}}$
$13.0(1.8)$
$0.98(0.10)$
10.6
$4.2(5.5)$
$2.8(1.9)^{\mathrm{a}}$
3.8
13.9
$144(20)^{\mathrm{a}} / 93(12)^{\mathrm{a}, \mathrm{b}}$
$136(19)^{\mathrm{a}} / 84(12)^{\mathrm{a}}$
$135(20)^{\mathrm{a}} / 79(13)^{\mathrm{a}}$

Results shown as mean (s.D.)

a $P<0.05$ vs tertile $1 ;{ }^{b} P<0.05$ vs tertile 2

Plasma PTH was above the reference limit in 52 participants (range 7.0-19.7 pmol/L), plasma total calcium in 20 participants (range $2.52-2.98 \mathrm{mmol} / \mathrm{L}$ ), and both PTH and calcium were elevated in 5 participants. Elevated calcium with normal PTH was observed in 15 subjects, and elevated PTH with normal calcium was observed in 47 subjects.

The mean values of fasting blood and plasma biochemistry were within the reference limits except for total and LDL cholesterol that were slightly above the upper reference limits in tertiles 2 and 3 (Table 2). Plasma total calcium concentrations did not differ, whereas phosphate was lower in PTH tertile 3 than in tertiles 1 and 2, and $25(\mathrm{OH}) \mathrm{D}_{3}$ was lower in PTH tertiles 2 and 3 than in tertile 1 . Creatinine did not differ, but plasma cystatin $\mathrm{C}$ was higher and estimated GFR lower in PTH tertiles 2 and 3 than in tertile 1. Uric acid, ALT and ALP were higher in PTH tertile 3 than in tertile 1 . In tertile 3 ALP was also higher than in tertile 2 . There were no differences in plasma sodium, potassium, renin or aldosterone concentrations, but total and LDL cholesterol were higher in the PTH tertiles 2 and 3 vs tertile 1, while HDL cholesterol was higher in tertile 3 vs tertiles 1 and 2 . Fasting plasma glucose was higher in PTH tertiles 2 and 3 than in tertile 1, and QUICKI was lower in PTH tertile 3 than in tertile 1.

\section{Supine and upright haemodynamics in tertiles of plasma PTH}

Due to the above differences between the PTH tertiles, the MANOVA for repeated measures analyses were adjusted for age, BMI, QUICKI, dairy product consumption, estimated
GFR, and plasma phosphate, $25(\mathrm{OH})_{2} \mathrm{D}_{3}$, uric acid, ALT, ALP, LDL cholesterol, and triglycerides.

The analyses showed significant differences between the PTH tertiles in upright aortic systolic BP (Fig. 1A), and supine and upright aortic diastolic BP and AIx (Fig. 1B and C). In post hoc analyses aortic diastolic BP and AIx were higher in PTH tertile 3 than in tertile 1. No differences were detected in the forward pressure wave between the tertiles $(P=0.336)$.

PWV (Fig. 1D), and supine and upright heart rate (Fig. 2A) and cardiac output (Fig. 2B) were corresponding in all PTH tertiles, and so were ECW volume $(P=0.135)$ and ECW balance $(P=0.580)$ even after all above adjustments. Stroke volume or left ventricular ejection duration were also corresponding in the PTH tertiles ( $P=0.204$ and $P=0.802$, respectively). In contrast, SVR presented with significant differences between the PTH tertiles, and a significant linear time-interaction was also observed $(P=0.031)$ indicating that the difference in SVR was especially noticeable during the upright posture (Fig. 2C). In post hoc analyses SVR was higher in PTH tertile 3 vs tertile 1 .

In the HRV analyses, HF power was significantly reduced $(P<0.001)$ and LF/HF ratio increased $(P<0.001)$ in the upright vs the supine position. However, the HRV indices HF power, LF power, and LF/HF ratio did not present with any significant differences between the PTH tertiles during either supine or upright posture (Fig. 3) ( $P>0.099$ for all comparisons).

Exclusion of the five subjects with elevated calcium and PTH values, or the 20 subjects with elevated 
Table 2 Fasting blood and plasma biochemistry results in tertiles of plasma parathyroid hormone concentration adjusted for sex.

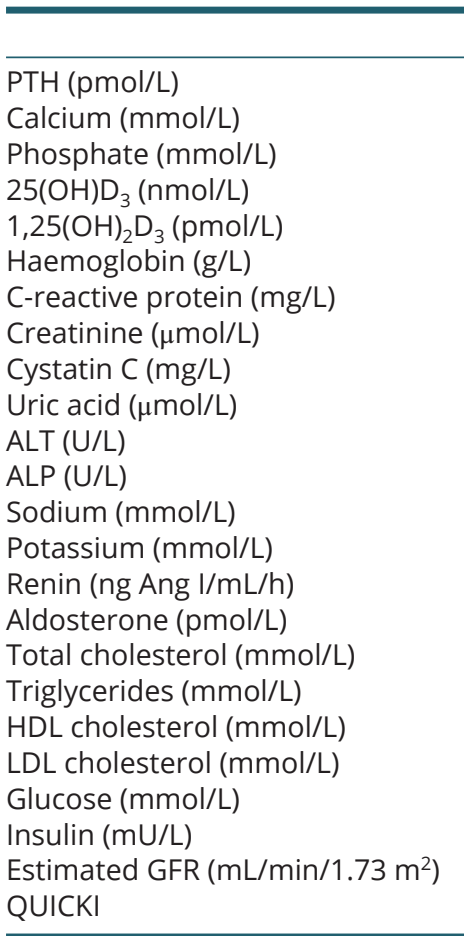

\begin{tabular}{r}
\hline PTH tertile $\mathbf{1}(n=206)$ \\
\hline $3.0(3.0-3.1)$ \\
$2.3(2.3-2.3)$ \\
$1.0(1.0-1.0)$ \\
$82(76-88)$ \\
$107(102-112)$ \\
$144(142-146)$ \\
$1.6(1.2-2.2)$ \\
$74(73-76)$ \\
$0.8(0.8-0.8)$ \\
$290(280-300)$ \\
$27(25-29)$ \\
$58(56-60)$ \\
$140(140-1416)$ \\
$3.8(3.8-3.9)$ \\
$1.0(0.9-1.1)$ \\
$518(470-567)$ \\
$5.0(4.8-5.1)$ \\
$1.2(1.0-1.3)$ \\
$1.6(1.6-1.7)$ \\
$2.9(2.7-3.0)$ \\
$5.3(5.3-5.4)$ \\
$7.5(7.8-8.3)$ \\
$103(100-105)$ \\
$0.365(0.356-0.374)$
\end{tabular}

\begin{tabular}{c}
\hline PTH tertile $2(n=208)$ \\
\hline $4.3(4.2-4.3)^{\mathrm{a}}$ \\
$2.3(2.3-2.3)$ \\
$1.0(1.0-1.0)$ \\
$70(65-75)^{\mathrm{a}}$ \\
$108(103-113)$ \\
$144(143-146)$ \\
$1.6(1.3-1.8)$ \\
$73(72-75)$ \\
$0.9(0.8-0.9)^{\mathrm{a}}$ \\
$307(297-317)$ \\
$30(27-33)$ \\
$60(58-63)$ \\
$140(140-141)$ \\
$3.8(3.8-3.9)$ \\
$1.0(0.8-1.1)$ \\
$493(458-528)$ \\
$5.2(5.1-5.4)^{\mathrm{a}}$ \\
$1.2(1.2-1.3)$ \\
$1.6(1.5-1.7)$ \\
$3.1(3.0-3.2)^{\mathrm{a}}$ \\
$5.5(5.4-5.6)^{\mathrm{a}}$ \\
$8.2(7.3-9.0)$ \\
$97(95-100)^{\mathrm{a}}$ \\
$0.354(0.349-0.359)$ \\
\end{tabular}

\begin{tabular}{c}
\hline PTH tertile $\mathbf{3}(n=208)$ \\
\hline $6.5(6.3-6.8)^{\mathrm{a}, \mathrm{b}}$ \\
$2.3(2.3-2.3)$ \\
$0.9(0.9-0.9)^{\mathrm{a}, \mathrm{b}}$ \\
$63(59-67)^{\mathrm{a}}$ \\
$110(105-115)$ \\
$145(143-146)$ \\
$1.8(1.5-2.2)$ \\
$74(72-76)$ \\
$0.9(0.8-0.9)^{\mathrm{a}}$ \\
$313(302-325)^{\mathrm{a}}$ \\
$33(30-37)^{\mathrm{a}}$ \\
$66(64-69)^{\mathrm{a}, \mathrm{b}}$ \\
$141(140-141)$ \\
$3.8(3.7-3.8)$ \\
$1.0(0.8-1.1)$ \\
$519(449-588)$ \\
$5.3(5.1-5.4)^{\mathrm{a}}$ \\
$1.4(1.2-1.6)^{\mathrm{a}}$ \\
$1.5(1.5-1.6)$ \\
$3.2(3.1-3.3)^{\mathrm{a}}$ \\
$5.5(5.5-5.6)^{\mathrm{a}}$ \\
$11.4(7.5-15.2)$ \\
$96(94-99)^{\mathrm{a}}$ \\
$0.349(0.342-0.356)^{\mathrm{a}}$ \\
\end{tabular}

Results shown as mean $(95 \% \mathrm{Cl}$ of the mean). Due to missing values, all blood and plasma biochemistry results were available in tertile 1 for 197 subjects, in tertile 2 for 194 subjects, and in tertile 3 for 186 subjects.

a $P<0.05$ vs tertile $1 ;{ }^{b} P<0.05$ vs tertile 2 .

1,25(OH) $\mathrm{D}_{3}, 1,25$-dihydroxyvitamin $\mathrm{D}_{3} ; 25(\mathrm{OH}) \mathrm{D}_{3}$, 25-hydroxyvitamin $\mathrm{D}_{3} ; \mathrm{ALP}$, alkaline phosphatase; ALT, alanine aminotransferase; GFR, glomerular filtration rate (estimated by cystatin C based CKD-EPI formula); HDL, high-density lipoprotein; LDL, low-density lipoprotein; PTH, parathyroid hormone; QUICKI, quantitative insulin sensitivity check index.

calcium concentration, did not alter the results. In the 47 participants with probable normocalcemic hyperparathyroidism (elevated PTH and normal plasma calcium), a significant correlation was observed between PTH and mean aortic diastolic BP $\left(\mathrm{r}_{\mathrm{P}}=0.355, P=0.014\right)$, but not between PTH and mean aortic systolic BP.

\section{Explanatory variables for haemodynamic variables in linear regression analyses}

Potential explanatory factors for the mean values of the haemodynamic variables during the 10-min recording period were examined using multivariable linear regression analyses. These analyses showed that plasma PTH concentration was an independent explanatory variable for aortic systolic BP, aortic diastolic BP, AIx, and SVR (Table 3). Plasma PTH concentration was not an explanatory variable for cardiac output or PWV (data not shown).

If the five subjects with elevated calcium and PTH values were excluded, PTH remained a significant explanatory variable for aortic systolic and diastolic BP $(P<0.001$ for both), SVR $(P=0.015)$ and AIx $(P=0.001)$. If the
20 subjects with elevated plasma calcium concentration were excluded, the results did not change significantly, either (data not shown).

When the regression analyses were performed separately for men and women, plasma PTH was an independent explanatory variable of aortic systolic BP in men (beta $=0.169, P=0.004)$ but not in women $(P=0.197)$, while PTH was a significant explanatory variable for aortic diastolic BP in both men (beta $=0.137, P=0.019$ ) and in women (beta $=0.126, P=0.042$ ).

\section{Discussion}

Our results for the first time showed that subjects divided to tertiles of plasma PTH concentration presented with differences in supine and upright central diastolic BP, wave reflection, and upright central systolic BP. Moreover, a direct relation between PTH and SVR was observed during the vasoconstriction induced by upright posture. Higher BMI is associated with higher BP (1), while we found that PTH correlated with BMI in the obese and overweight

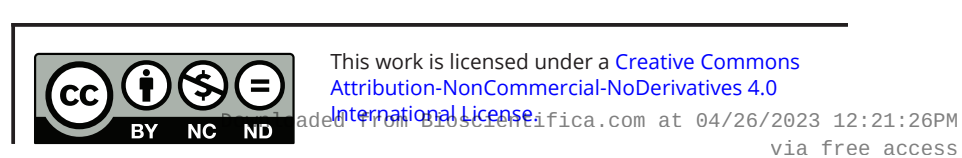



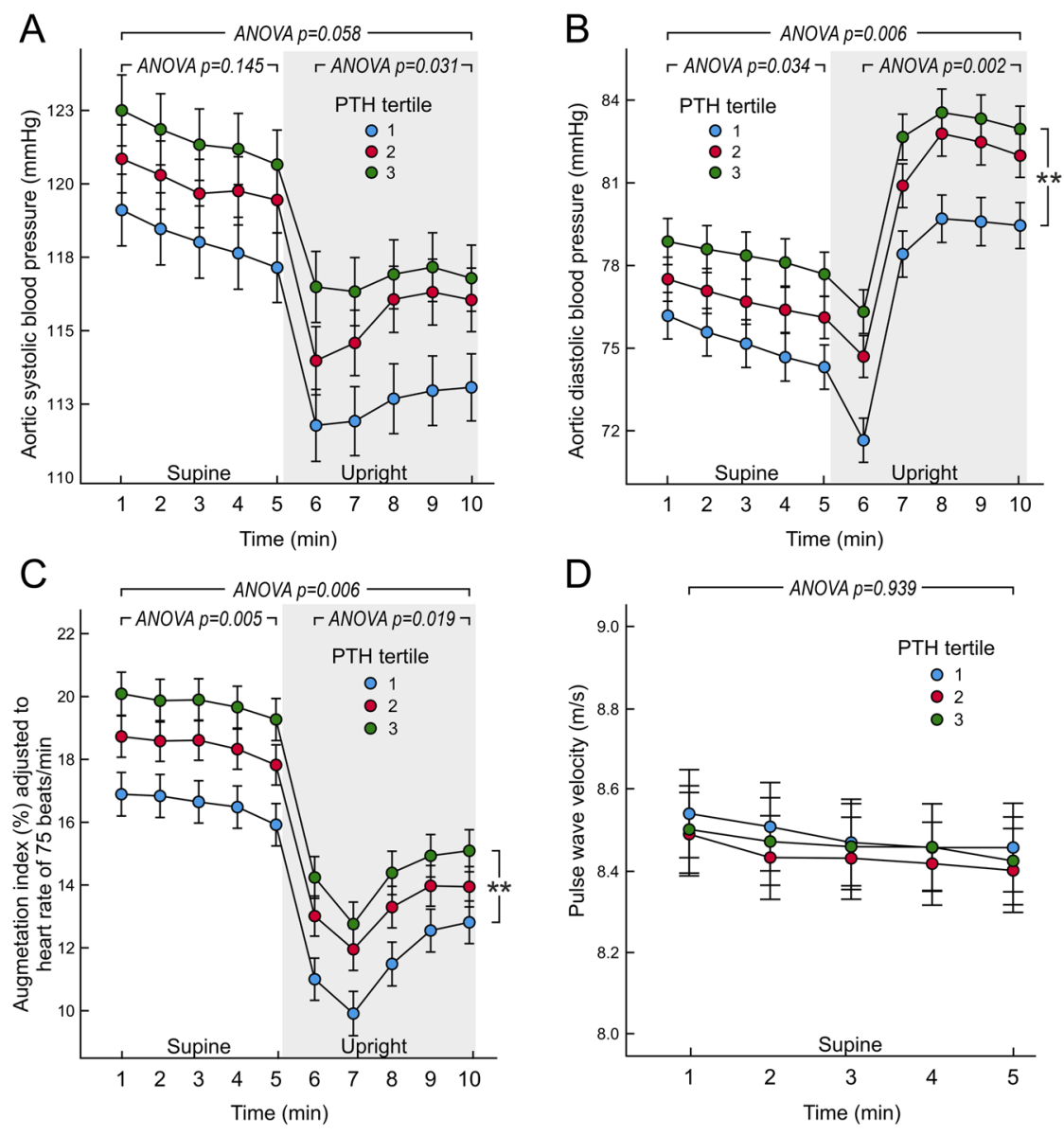
Figure 1
Aortic systolic blood pressure (A), diastolic blood pressure (B), augmentation index adjusted to heart rate of 75 b.p.m. (C), and pulse wave velocity (D) in tertiles of plasma parathyroid hormone concentration adjusted for sex; mean (circle) with S.E.M. (whiskers), multivariable ANOVA for repeated measures with the Bonferroni correction. The covariates were age, body mass index, quantitative insulin sensitivity check index, dairy product consumption, estimated glomerular filtration rate, and plasma concentrations of phosphate, 25-hydroxyvitamin $\mathrm{D}_{3}$, uric acid, alanine aminotransferase, alkaline phosphatase, low-density lipoprotein cholesterol, and triglycerides. ${ }^{*} P<0.01$ tertile 3 vs tertile 1 during the $10 \mathrm{~min}$ of recording.

subjects, but not in normal weight participants. The regression analyses confirmed that PTH was directly related with central $\mathrm{BP}$, wave reflection, and SVR, but not with cardiac output, or indices of large artery stiffness and HRV.

All study subjects were without secondary hypertension (24), cardiovascular, renal, or liver diseases, diabetes, or medications with direct cardiovascular influences. Plasma PTH and calcium concentrations were not among the exclusion criteria. Five subjects presented with elevated PTH and calcium, 15 presented with elevated calcium but normal PTH, while 47 presented with elevated PTH but normal plasma calcium concentration suggesting the presence of normocalcemic hyperparathyroidism. Dairy product consumption was lowest in PTH tertile 3 , plasma $25(\mathrm{OH}) \mathrm{D}_{3}$ was highest in the PTH tertile 1, while no differences in plasma 1,25-dihydroxyvitamin $\mathrm{D}_{3}\left(1,25(\mathrm{OH})_{2} \mathrm{D}_{3}\right)$ or total calcium concentrations were detected between the tertiles. These findings were expected, considering the feedback systems of calcium regulatory hormones (23). The differences in the metabolic profiles between the highest vs lowest
PTH tertiles closely resemble the metabolic alterations reported in patients with normocalcemic primary hyperparathyroidism vs controls (35).

In experimental animals $1,25(\mathrm{OH})_{2} \mathrm{D}_{3}$ is a negative regulator of the renin-angiotensin-aldosterone system (RAAS) (36). Also in humans, lower plasma levels of $25(\mathrm{OH}) \mathrm{D}_{3}$ and $1,25(\mathrm{OH})_{2} \mathrm{D}_{3}$ have been associated with elevated renin and angiotensin II concentrations, but many of the study subjects were concomitantly exposed to medications influencing RAAS activity (37). In spite of the reported bidirectional relationship between PTH and the RAAS $(38,39)$, we did not observe differences in plasma renin and aldosterone concentrations, or in volume homeostasis (ECW and ECW balance), between the PTH tertiles. These findings correspond to the matching $1,25(\mathrm{OH})_{2} \mathrm{D}_{3}$ concentrations in all tertiles, as the active vitamin $\mathrm{D}$ metabolite down-regulates renin expression via the vitamin D receptor (36). Our observations correspond to a German study showing no associations between plasma PTH and renin and aldosterone concentrations in a large cohort of general population (12). 
A

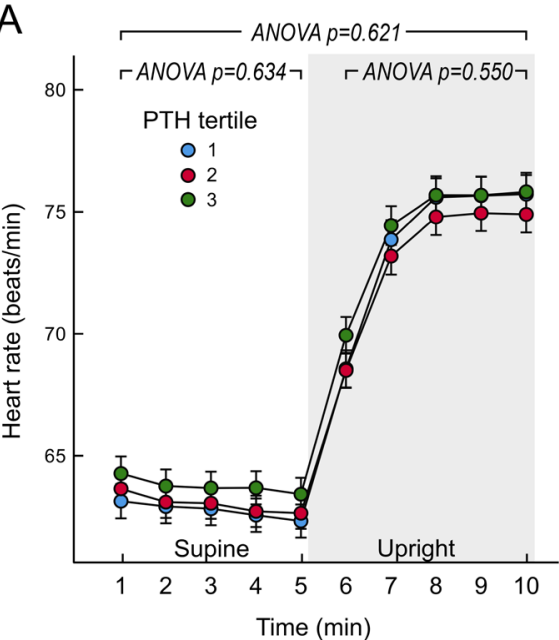

B

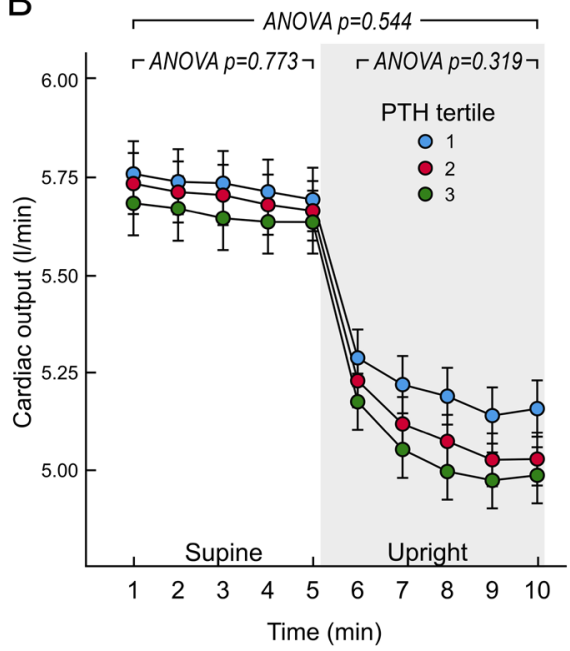

C

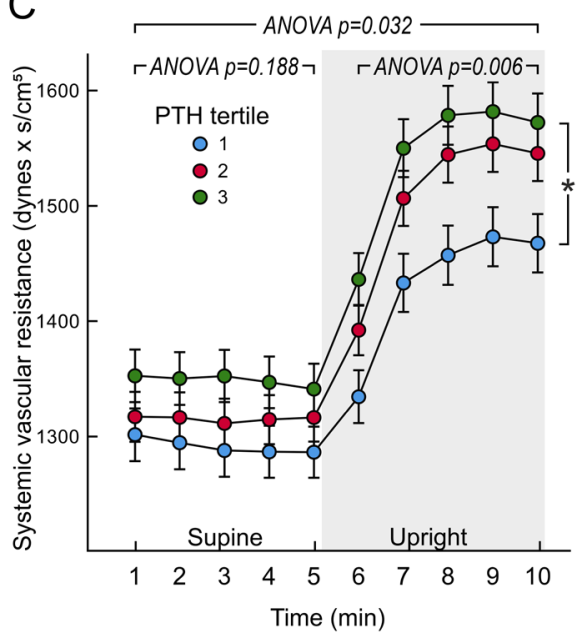

Figure 2

Heart rate (A), cardiac output (B), and systemic vascular resistance (C) in tertiles of plasma parathyroid hormone concentration adjusted for sex; mean (circle) with S.E.M. (whiskers), multivariable ANOVA for repeated measures with the Bonferroni correction. Covariates as in Fig. 1. $\star P<0.05$, tertile 3 vs. tertile 1 during the 10 min of recording.
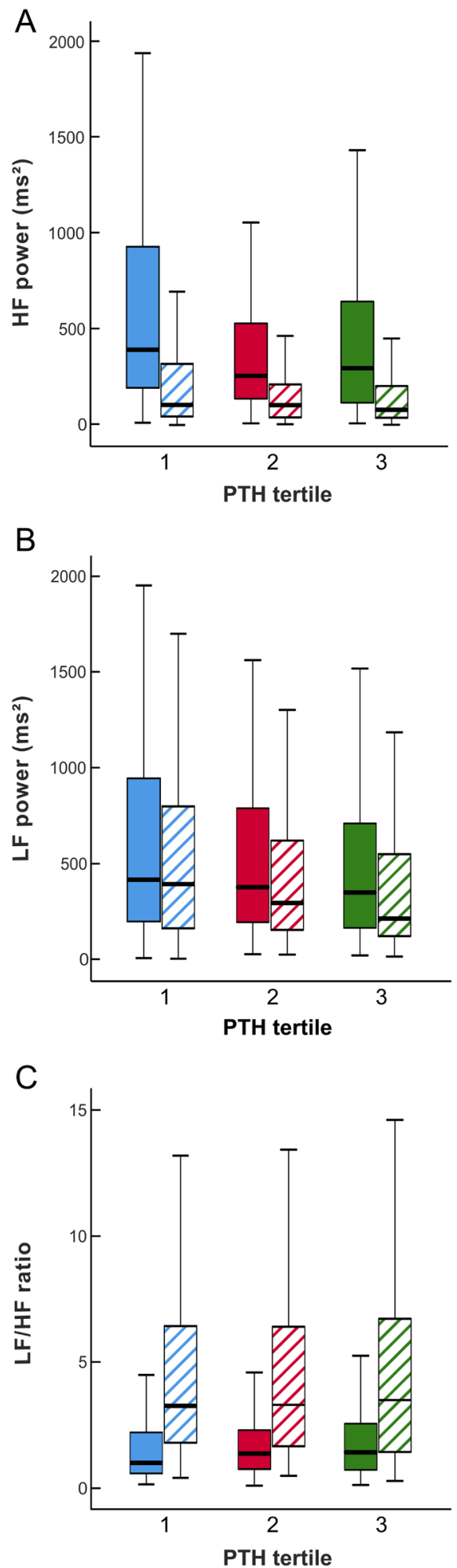

Figure 3

Heart rate variability in supine (solid boxes) and upright (striped boxes) positions: high-frequency power (A), low-frequency power (B), and low-frequency - high-frequency ratio (C) in tertiles of plasma parathyroid hormone concentration adjusted for sex; median (thick line inside box), 25th to 75th percentile (box), and range (whiskers, outliers omitted). 
Table 3 Significant explanatory variables for aortic systolic and diastolic blood pressures, augmentation index (adjusted to heart rate of 75 b.p.m.), and systemic vascular resistance in linear regression analysis.

\begin{tabular}{l}
\hline Aortic systolic blood pressure \\
\hline Model $\left(\mathrm{R}^{2}=0.400\right)$ \\
(constant) \\
PWV \\
Estimated GFR \\
Calcium \\
BMI \\
LDL \\
PTH (Lg L $\left._{10}\right)$ \\
ECW balance \\
\\
\hline Augmentation index (adjusted \\
to heart rate of 75 b.p.m.) \\
\hline Model ( $\left.{ }^{2}=0.567\right)$ \\
(constant) \\
Age \\
Sex (male) \\
Smoking (present) \\
PTH (Lg 10 ) \\
LDL cholesterol \\
CRP (Lg $\left(g_{10}\right)$ \\
\end{tabular}

\begin{tabular}{rllll}
\hline \multicolumn{1}{c}{$\mathbf{B}$} & & Beta & & \multicolumn{1}{c}{$\boldsymbol{P}$} \\
\cline { 1 - 1 }-0.545 & & & \\
2.969 & & 0.315 & & $<0.001$ \\
-0.163 & & 0.163 & & $<0.001$ \\
26.461 & & 0.16 & & $<0.001$ \\
0.604 & & 0.146 & & 0.001 \\
2.295 & & 0.121 & & 0.007 \\
14.249 & & 0.12 & & 0.003 \\
14.315 & & 0.082 & & 0.037
\end{tabular}

\begin{tabular}{l}
\hline Aortic diastolic blood pressure \\
\hline Model $\left(R^{2}=0.391\right)$ \\
(constant) \\
PWV \\
Estimated GFR \\
Calcium \\
LDL cholesterol \\
Age \\
PTH (Lg $\left.{ }_{10}\right)$ \\
Phosphate \\
BMI \\
Alcohol, drinks per week ( $\left.\operatorname{Lg}_{10}\right)$ \\
\hline \\
Systemic vascular resistance \\
\hline Model ( $\left.{ }^{2}=0.264\right)$ \\
(constant) \\
Sex (male) \\
Age \\
Calcium \\
ECW balance \\
Smoking (previous) \\
PTH (Lg 10 \\
Vitamin D supplement use
\end{tabular}

\begin{tabular}{|c|c|c|}
\hline B & Beta & $P$ \\
\hline 28.046 & & \\
\hline 1.984 & 0.31 & $<0.001$ \\
\hline-0.114 & -0.168 & 0.001 \\
\hline 15.944 & 0.143 & 0.001 \\
\hline 1.716 & 0.134 & 0.004 \\
\hline-0.135 & -0.129 & 0.021 \\
\hline 9.573 & 0.119 & 0.005 \\
\hline-7.79 & -0.106 & 0.014 \\
\hline 0.286 & 0.103 & 0.022 \\
\hline 2.865 & 0.1 & 0.012 \\
\hline B & Beta & $P$ \\
\hline 44.021 & & \\
\hline-201.93 & -0.324 & $<0.001$ \\
\hline 6.251 & 0.235 & $<0.001$ \\
\hline 382.502 & 0.134 & 0.002 \\
\hline 354.311 & 0.118 & 0.009 \\
\hline 73.793 & 0.109 & 0.013 \\
\hline 199.785 & 0.098 & 0.031 \\
\hline 73.631 & 0.087 & 0.042 \\
\hline
\end{tabular}

Variables in Model: age, sex, BMI, estimated GFR (CKD-EPI-Cystatin C), ECW balance, $\mathrm{Lg}_{10}$ of alcohol consumption, $\mathrm{Lg}_{10}$ of dairy product consumption, smoking status, vitamin D supplement use, $\mathrm{Lg}_{10}$ of fasting plasma glucose, $\mathrm{Lg}_{10}$ of fasting plasma insulin, $\mathrm{Lg}_{10}$ of C-reactive protein, $\mathrm{Lg}_{10}$ of PTH, calcium, phosphate, $\mathrm{Lg}_{10}$ of $25(\mathrm{OH}) \mathrm{D}_{3}$, sodium, uric acid, $\mathrm{Lg}_{10}$ of alkaline phosphatase, $\mathrm{Lg}_{10}$ of alanine aminotransferase, $\mathrm{LDL}$ cholesterol, $\mathrm{HDL}$ cholesterol, $\mathrm{Lg}_{10}$ of triglycerides, $\mathrm{Lg}_{10}$ of renin, $\mathrm{Lg}_{10}$ of aldosterone, and PWV (PWV not for systemic vascular resistance).

CRP, C-reactive protein; ECW, extra-cellular water; GFR, glomerular filtration rate; LDL, low-density lipoprotein; PTH, parathyroid hormone; PWV, pulse wave velocity.

PTH has been directly associated with the level of peripheral BP $(2,3)$, and the risk of hypertension in patients with primary hyperparathyroidism $(4,40)$ and in the general population $(5,40)$. In 3620 Norwegian normocalcemic subjects with normal kidney function and without antihypertensive medications, PTH was directly related with peripheral systolic and diastolic BP (3). Similar results were found in a large U.S. cohort of subjects (2). However, central aortic BP, rather than peripheral BP, better reflects the pressure load to the vital organs heart, kidneys and the brain, and may be more relevant for the pathogenesis of cardiovascular diseases $(41,42)$.

Patients with primary hyperparathyroidism may present with increased PWV (i.e. large artery stiffness) (43). However, two case-control studies found no differences in PWV between patients with hyperparathyroidism and controls $(44,45)$, and some smaller studies reported no associations between PTH and PWV $(43,46)$. However, in a Chinese study with 1052 untreated subjects, higher plasma PTH was associated with increased PWV independent of the level of BP (14). Three population studies in elderly subjects likewise reported a direct association between
PTH and large artery stiffness. The relation, however, was attenuated when analyses were adjusted for BP (13, $15,47)$. In the present study, no association was found between plasma PTH and PWV.

Central BP is influenced by forward waves and backward waves reflected from the peripheral circulation (48). Forward wave amplitude is significantly influenced by aortic stiffness, and is also the major determinant of central pulse pressure $(49,50)$. In the present study, forward wave amplitude did not differ between the plasma PTH tertiles, consistent with the finding of unaltered PWV. The magnitude and timing of the backward waves are determined by characteristics of the whole arterial bed (51). The wave reflections occur from multiple locations in the arterial system, the dominating regions being the terminal abdominal aorta $(52,53)$ and highresistance arterioles $(54,55)$. The variable AIx quantifies the augmentation of the central pulse pressure due to wave reflection (50). AIx has been reported to predict cardiovascular events and mortality independently of peripheral BP (56). Previous results concerning wave reflection and PTH have been conflicting, showing either 
unchanged $(45,46)$ or increased AIx patients with primary hyperparathyroidism $(17,57)$. In the present study, AIx was higher in the PTH tertile 3 than in tertile 1 , while PTH was also an explanatory factor for AIx in the regression analysis.

We found that SVR was increased in the highest vs lowest PTH tertile, and the regression analysis confirmed the relation between plasma PTH and SVR. In contrast, no differences in heart rate, cardiac output, or cardiac autonomic tone (HRV) were observed between the PTH tertiles. These results indicate that the influence of PTH on BP was mediated via an effect on SVR. Notably, the elevating influence of PTH on SVR was especially observed during the head-up tilt, which was also characterised by the activation of the sympathetic nervous system, as documented by increased cardiac sympathovagal balance (LF/HF ratio). Our findings are complemented by previous reports showing that PTH increases vascular reactivity to the effects mediated by the sympathetic nervous system, endocrine factors, and the RAAS $(16,20,21)$.

The present direct association between PTH and AIx can be explained by the observed increase in SVR. In addition to large arterial stiffness and the pattern of left ventricular ejection, the magnitude of AIx is influenced by resistance vessel tone (58). Indeed, AIx was associated with the level of peripheral arterial resistance in subjects without antihypertensive medications (55). Furthermore, vasoconstriction induced by angiotensin II increases AIx, whereas vasodilatation induced by nitroglycerin reduces AIx, independent of the level of aortic PWV (58). The possibility that the association of PTH with AIx was secondary to changes in cardiac function was excluded by the findings that neither stroke volume nor ejection duration were associated to PTH.

The association between SVR, AIx and PTH may be related to changes in endothelium-mediated arterial tone $(4,13,59)$. Endothelial function has been reported to inversely correlate with the magnitude of AIx in healthy subjects (59). In a large cohort without cardiovascular diseases, higher PTH associated with lower flow-mediated dilation, independent of serum calcium and $25(\mathrm{OH}) \mathrm{D}_{3}$ concentrations or estimated GFR, a finding relating impaired endothelial function with higher level of PTH (13). Our findings associating higher plasma PTH with increased central BP and AIx could explain the reported link between increased PTH, higher left ventricular mass, and risk of incident heart failure (60).

Our study has limitations. The cross-sectional design does not allow conclusions of causality, and selection bias caused by the recruitment of voluntary subjects cannot be excluded. Although comprehensive adjustment for confounders was performed, many of the clinical and biochemical variables are closely correlated, leading to a potential multicollinearity problem. Our analyses were based on plasma total calcium concentrations, and information about plasma ionised calcium or urinary calcium excretion was not available. We applied noninvasive indirect methods for the haemodynamic measurements, and the results on stroke volume are based on mathematical processing of the bioimpedance signal (27), while central aortic BP and pulse wave reflections are derived from the tonometry signal (26). The strengths of our study are the comprehensive biochemistry analyses, adjustment for the use of vitamin $\mathrm{D}$ and calcium supplements and dairy products, and the simultaneous assessment of several haemodynamic variables (51).

To conclude, plasma PTH concentration was directly related to central BP, SVR and wave reflection in normotensive or never-treated hypertensive subjects without cardiovascular comorbidities and medications. Elevated plasma PTH concentration may play a role in the pathophysiology of primary hypertension.

\section{Supplementary materials}

This is linked to the online version of the paper at https://doi.org/10.1530/ EC-20-0446.

\section{Declaration of interest}

The authors declare that there is no conflict of interest that could be perceived as prejudicing the impartiality of the research reported.

\section{Funding}

This work was supported by Competitive State Research Financing of the Expert Responsibility Area of Tampere University Hospital (Grants 9V054 and 9X046); Finnish Foundation for Cardiovascular Research; Päivikki and Sakari Sohlberg Foundation; Paavo Nurmi Foundation; Pirkanmaa Regional Fund of the Finnish Cultural Foundation; and Aarne Koskelo Foundation.

\section{Acknowledgements}

The authors thank Paula Erkkilä, RN, Reeta Kulmala, RN, for invaluable technical assistance and Heini Huhtala, MSc, for statistical support. The authors wish to acknowledge CSC - IT Center for Science, Finland, for computational resources.

\section{References}

1 Carretero OA \& Oparil S. Essential hypertension: part I: definition and etiology. Circulation 2000101 329-335. (https://doi. org/10.1161/01.cir.101.3.329) 
2 Zhao G, Ford ES, Li C, Kris-Etherton PM, Etherton TD \& Balluz LS. Independent associations of serum concentrations of 25-hydroxyvitamin D and parathyroid hormone with blood pressure among US adults. Journal of Hypertension 201028 1821-1828. (https://doi.org/10.1097/HJH.0b013e32833bc5b4)

3 Saleh F, Jorde R, Svartberg J \& Sundsfjord J. The relationship between blood pressure and serum parathyroid hormone with special reference to urinary calcium excretion: the Tromsø study. Journal of Endocrinological Investigation 200629 214-220. (https://doi. org/10.1007/BF03345542)

4 Pepe J, Cipriani C, Sonato C, Raimo O, Biamonte F \& Minisola S. Cardiovascular manifestations of primary hyperparathyroidism: a narrative review. European Journal of Endocrinology $2017 \mathbf{1 7 7}$ R297-R308. (https://doi.org/10.1530/EJE-17-0485)

5 Zhang Y \& Zhang DZ. Circulating parathyroid hormone and risk of hypertension: a meta-analysis. Clinica Chimica Acta: International Journal of Clinical Chemistry $2018 \mathbf{4 8 2}$ 40-45. (https://doi. org/10.1016/j.cca.2018.03.028)

6 Monego G, Arena V, Pasquini S, Stigliano E, Fiaccavento R, Leone O, Arpesella G, Potena L, Ranelletti FO, Nardo PD, et al. Ischemic injury activates PTHrP and PTH1R expression in human ventricular cardiomyocytes. Basic Research in Cardiology 2009104 427-434. (https://doi.org/10.1007/s00395-008-0774-4)

7 Okano K, Wu S, Huang X, Pirola CJ, Juppner H, Abou-Samra AB, Segre GV, Iwasaki K, Fagin JA \& Clemens TL. Parathyroid hormone (PTH)/PTH-related protein (PTHrP) receptor and its messenger ribonucleic acid in rat aortic vascular smooth muscle cells and UMR osteoblast-like cells: cell-specific regulation by angiotensin-II and PTHrP. Endocrinology 1994135 1093-1099. (https://doi.org/10.1210/ endo.135.3.8070351)

8 Jiang B, Morimoto S, Yang J, Niinoabu T, Fukuo K \& Ogihara T. Expression of parathyroid hormone/parathyroid hormone-related protein receptor in vascular endothelial cells. Journal of Cardiovascular Pharmacology 199831 (Supplement 1) S142-S144. (https://doi. org/10.1097/00005344-199800001-00042)

9 Pang PK, Tenner TE, Yee JA, Yang M \& Janssen HF. Hypotensive action of parathyroid hormone preparations on rats and dogs. PNAS 198077 675-678. (https://doi.org/10.1073/pnas.77.1.675)

10 Fliser D, Franek E, Fode P, Stefanski A, Schmitt CP, Lyons M \& Ritz E. Subacute infusion of physiological doses of parathyroid hormone raises blood pressure in humans. Nephrology, Dialysis, Transplantation 199712 933-938. (https://doi.org/10.1093/ndt/12.5.933)

11 Brown J, de Boer IH, Robinson-Cohen C, Siscovick DS, Kestenbaum B, Allison M \& Vaidya A. Aldosterone, parathyroid hormone, and the use of renin-angiotensin-aldosterone system inhibitors: the Multi-Ethnic Study of Atherosclerosis. Journal of Clinical Endocrinology and Metabolism 2015100 490-499. (https://doi. org/10.1210/jc.2014-3949)

12 Fischer E, Hannemann A, Rettig R, Lieb W, Nauck M, Pallauf A, Bildingmaier M, Beuschlein F, Wallaschofski H \& Reincke M. A high aldosterone to renin ratio is associated with high serum parathyroid hormone concentrations in the general population. Journal of Clinical Endocrinology and Metabolism 201499 965-971. (https://doi. org/10.1210/jc.2013-3214)

13 Bosworth C, Sachs MC, Duprez D, Hoofnagle AN, Ix JH, Jacobs DR, Peralta CA, Siscovick DS, Kestenbaum B \& de Boer IH. Parathyroid hormone and arterial dysfunction in the multi-ethnic study of atherosclerosis. Clinical Endocrinology 201379 429-436. (https://doi. org/10.1111/cen.12163)

14 Cheng YB, Li LH, Guo QH, Li FK, Huang QF, Sheng CS, Wang JG, Staessen JA \& Li Y. Independent effects of blood pressure and parathyroid hormone on aortic pulse wave velocity in untreated Chinese patients. Journal of Hypertension 201735 1841-1848. (https://doi.org/10.1097/HJH.0000000000001395)

15 Gepner AD, Colangelo LA, Blondon M, Korcarz CE, de Boer IH, Kestenbaum B, Siscovick DS, Kaufman JD, Liu K \& Stein JH.
25-Hydroxyvitamin D and parathyroid hormone levels do not predict changes in carotid arterial stiffness: the MultiEthnic Study of Atherosclerosis. Arteriosclerosis, Thrombosis, and Vascular Biology 201434 1102-1109. (https://doi.org/10.1161/ ATVBAHA.113.302605)

16 Schiffl H \& Lang SM. Hypertension secondary to PHPT: cause or coincidence? International Journal of Endocrinology 20112011974647. (https://doi.org/10.1155/2011/974647)

17 Rubin MR, Maurer MS, McMahon DJ, Bilezikian JP \& Silverberg SJ. Arterial stiffness in mild primary hyperparathyroidism. Journal of Clinical Endocrinology and Metabolism 200590 3326-3330. (https:// doi.org/10.1210/jc.2004-1400)

18 Kosch M, Hausberg M, Vormbrock K, Kisters K, Gabriels G, Rahn KH \& Barenbrock M. Impaired flow-mediated vasodilation of the brachial artery in patients with primary hyperparathyroidism improves after parathyroidectomy. Cardiovascular Research 200047 813-818. (https://doi.org/10.1016/s0008-6363(00)00130-9)

19 Neunteufl T, Katzenschlager R, Abela C, Kostner K, Niederle B, Weidinger F \& Stefenelli T. Impairment of endothelium-independent vasodilation in patients with hypercalcemia. Cardiovascular Research 199840 396-401. (https://doi.org/10.1016/s0008-6363(98)00177-1)

20 Gennari C, Nami R \& Gonnelli S. Hypertension and primary hyperparathyroidism: the role of adrenergic and renin-angiotensinaldosterone systems. Mineral and Electrolyte Metabolism 199521 77-81.

21 Rodríguez-Portales JA \& Fardella C. Primary hyperparathyroidism and hypertension: persistently abnormal pressor sensitivity in normotensive patients after surgical cure. Journal of Endocrinological Investigation 199417 307-311. (https://doi.org/10.1007/BF03348986)

22 Oinonen L, Koskela J, Eräranta A, Tikkakoski A, Kähönen M, Niemelä O, Mustonen J \& Pörsti I. Plasma total calcium concentration is associated with blood pressure and systemic vascular resistance in normotensive and never-treated hypertensive subjects. Blood Pressure 202029 137-148. (https://doi.org/10.1080/08037051.2019.1696180)

23 Mundy GR \& Guise TA. Hormonal control of calcium homeostasis. Clinical Chemistry 199945 1347-1352. (https://doi.org/10.1093/ clinchem/45.8.1347)

24 Williams B, Mancia G, Spiering W, Agabiti Rosei E, Azizi M, Burnier M, Clement DL, Coca A, de Simone G, Dominiczak A, et al. 2018 ESC/ESH guidelines for the management of arterial hypertension. European Heart Journal 201839 3021-3104. (https:// doi.org/10.1093/eurheartj/ehy339)

25 Tikkakoski AJ, Tahvanainen AM, Leskinen MH, Koskela JK, Haring A, Viitala J, Kähönen MAP, Kööbi T, Niemelä O, Mustonen JT, et al. Hemodynamic alterations in hypertensive patients at rest and during passive head-up tilt. Journal of Hypertension 201331 906-915. (https://doi.org/10.1097/HJH.0b013e32835ed605)

26 Chen CH, Nevo E, Fetics B, Pak PH, Yin FC, Maughan WL \& Kass DA. Estimation of central aortic pressure waveform by mathematical transformation of radial tonometry pressure. Validation of generalized transfer function. Circulation 199795 1827-1836. (https://doi.org/10.1161/01.cir.95.7.1827)

27 Kööbi T, Kaukinen S, Turjanmaa VM \& Uusitalo AJ. Wholebody impedance cardiography in the measurement of cardiac output. Critical Care Medicine 199725 779-785. (https://doi. org/10.1097/00003246-199705000-00012)

28 Kööbi T, Kähönen M, Iivainen T \& Turjanmaa V. Simultaneous non-invasive assessment of arterial stiffness and haemodynamics - a validation study. Clinical Physiology and Functional Imaging 200323 31-36. (https://doi.org/10.1046/j.1475-097x.2003.00465.x)

29 Tahvanainen A, Koskela J, Tikkakoski A, Lahtela J, Leskinen M, Kähönen M, Nieminen T, Kööbi T, Mustonen J \& Pörsti I. Analysis of cardiovascular responses to passive head-up tilt using continuous pulse wave analysis and impedance cardiography. Scandinavian Journal of Clinical and Laboratory Investigation 200969 128-137. (https://doi.org/10.1080/00365510802439098) 
30 Pagani M, Lombardi F, Guzzetti S, Rimoldi O, Furlan R, Pizzinelli P, Sandrone G, Malfatto G, Dell'Orto S \& Piccaluga E. Power spectral analysis of heart rate and arterial pressure variabilities as a marker of sympatho-vagal interaction in man and conscious dog. Circulation Research 198659 178-193. (https://doi.org/10.1161/01. res.59.2.178)

31 Task Force of the European Society of Cardiology and the North American Society of Pacing and Electrophysiology. Heart rate variability: standards of measurement, physiological interpretation and clinical use. Task force of the European Society of Cardiology and the North American Society of Pacing and Electrophysiology. Circulation 199693 1043-1065. (https://doi.org/10.1161/01. CIR.93.5.1043

32 Parati G, Saul JP, Di Rienzo M \& Mancia G. Spectral analysis of blood pressure and heart rate variability in evaluating cardiovascular regulation: a critical appraisal. Hypertension 199525 1276-1286. (https://doi.org/10.1161/01.hyp.25.6.1276)

33 Malliani A, Pagani M, Lombardi F \& Cerutti S. Cardiovascular neural regulation explored in the frequency domain. Circulation 199184 482-492. (https://doi.org/10.1161/01.cir.84.2.482)

34 Inker LA, Schmid CH, Tighiouart H, Eckfeldt JH, Feldman HI, Greene T, Kusek JW, Manzi J, Van Lente F, Zhang YL, et al. Estimating glomerular filtration rate from serum creatinine and cystatin C. New England Journal of Medicine 2012367 20-29. (https://doi.org/10.1056/ NEJMoa1114248)

35 Hagström E, Lundgren E, Rastad J \& Hellman P. Metabolic abnormalities in patients with normocalcemic hyperparathyroidism detected at a population-based screening. European Journal of Endocrinology 2006155 33-39. (https://doi.org/10.1530/eje.1.02173)

36 Li YC, Kong J, Wei M, Chen ZF, Liu SQ \& Cao LP.

1,25-Dihydroxyvitamin D3 is a negative endocrine regulator of the renin-angiotensin system. Journal of Clinical Investigation $2002 \mathbf{1 1 0}$ 229-238. (https://doi.org/10.1172/JCI15219)

37 Tomaschitz A, Pilz S, Ritz E, Grammer T, Drechsler C, Boehm BO \& März W. Independent association between 1,25-dihydroxyvitamin D, 25-hydroxyvitamin D and the renin-angiotensin system: the Ludwigshafen Risk and Cardiovascular Health (LURIC) study. Clinica Chimica Acta: International Journal of Clinical Chemistry 2010411 1354-1360. (https://doi.org/10.1016/j.cca.2010.05.037)

38 Brown JM, Williams JS, Luther JM, Garg R, Garza AE, Pojoga LH, Ruan DT, Williams GH, Adler GK \& Vaidya A. Human interventions to characterize novel relationships between the renin-angiotensinaldosterone system and parathyroid hormone. Hypertension 201463 273-280. (https://doi.org/10.1161/HYPERTENSIONAHA.113.01910)

39 Tomaschitz A, Ritz E, Pieske B, Fahrleitner-Pammer A, Kienreich K, Horina JH, Drechsler C, Marz W, Ofner M, Pieber TR, et al. Aldosterone and parathyroid hormone: a precarious couple for cardiovascular disease. Cardiovascular Research 201294 10-19. (https://doi.org/10.1093/cvr/cvs092)

40 Kalla A, Krishnamoorthy P, Gopalakrishnan A, Garg J, Patel NC \& Figueredo VM. Primary hyperparathyroidism predicts hypertension: results from the National Inpatient Sample. International Journal of Cardiology 2017227 335-337. (https://doi.org/10.1016/j. ijcard.2016.11.080)

41 Agabiti-Rosei E, Mancia G, O’Rourke MF, Roman MJ, Safar ME, Smulyan H, Wang JG, Wilkinson IB, Williams B \& Vlachopoulos C. Central blood pressure measurements and antihypertensive therapy: a consensus document. Hypertension 200750 154-160. (https://doi. org/10.1161/HYPERTENSIONAHA.107.090068)

42 Kollias A, Lagou S, Zeniodi ME, Boubouchairopoulou N \& Stergiou GS. Association of central versus brachial blood pressure with target-organ damage: systematic review and meta-analysis. Hypertension 201667 183-190. (https://doi.org/10.1161/ HYPERTENSIONAHA.115.06066)

43 Rosa J, Raska I, Wichterle D, Petrak O, Strauch B, Somloova Z, Zelinka T, Holaj R \& Widimsky J. Pulse wave velocity in primary hyperparathyroidism and effect of surgical therapy. Hypertension Research 201134 296-300. (https://doi.org/10.1038/hr.2010.232)

44 Kosch M, Hausberg M, Barenbrock M, Posadzy-Malaczynska A, Kisters K \& Rahn KH. Arterial distensibility and pulse wave velocity in patients with primary hyperparathyroidism before and after parathyroidectomy. Clinical Nephrology 200155 303-308.

45 Tordjman KM, Yaron M, Izkhakov E, Osher E, Shenkerman G, Marcus-Perlman Y \& Stern N. Cardiovascular risk factors and arterial rigidity are similar in asymptomatic normocalcemic and hypercalcemic primary hyperparathyroidism. European Journal of Endocrinology 2010162 925-933. (https://doi.org/10.1530/EJE-091067)

46 Ring M, Farahnak P, Gustavsson T, Nilsson IL, Eriksson MJ \& Caidahl K. Arterial structure and function in mild primary hyperparathyroidism is not directly related to parathyroid hormone, calcium, or vitamin D. PLoS ONE 20127 e39519. (https://doi. org/10.1371/journal.pone.0039519)

47 Madero M, Wassel CL, Peralta CA, Najjar SS, Sutton-Tyrrell K, Fried LF, Boer IH de, Shlipak MG, Newman AB, Hausman D, et al. Markers of mineral metabolism are not associated with aortic pulse wave velocity in community-living elderly persons: the Health Aging and Body Composition Study. American Journal of Hypertension 201124 755-761. (https://doi.org/10.1038/ ajh.2011.43)

48 Westerhof N, Sipkema P, Bos GCVD \& Elzinga G. Forward and backward waves in the arterial system. Cardiovascular Research 19726 648-656. (https://doi.org/10.1093/cvr/6.6.648)

49 Mitchell GF, Parise H, Benjamin EJ, Larson MG, Keyes MJ, Vita JA, Vasan RS \& Levy D. Changes in arterial stiffness and wave reflection with advancing age in healthy men and women: the Framingham Heart Study. Hypertension 200443 1239-1245. (https://doi. org/10.1161/01.HYP.0000128420.01881.aa)

50 Nichols WW, Denardo SJ, Wilkinson IB, McEniery CM, Cockcroft J $\& O^{\prime}$ Rourke MF. Effects of arterial stiffness, pulse wave velocity, and wave reflections on the central aortic pressure waveform. Journal of Clinical Hypertension 200810 295-303. (https://doi.org/10.1111/ j.1751-7176.2008.04746.x)

51 Laurent S, Cockcroft J, Van Bortel L, Boutouyrie P, Giannattasio C, Hayoz D, Pannier B, Vlachopoulos C, Wilkinson I, StruijkerBoudier $\mathrm{H}$, et al. Expert consensus document on arterial stiffness: methodological issues and clinical applications. European Heart Journal 200627 2588-2605. (https://doi.org/10.1093/eurheartj/ ehl254)

52 Murgo JP, Westerhof N, Giolma JP \& Altobelli SA. Aortic input impedance in normal man: relationship to pressure wave forms. Circulation 198062 105-116. (https://doi.org/10.1161/01. cir.62.1.105)

53 Latham RD, Westerhof N, Sipkema P, Rubal BJ, Reuderink P \& Murgo JP. Regional wave travel and reflections along the human aorta: a study with six simultaneous micromanometric pressures. Circulation 198572 1257-1269. (https://doi.org/10.1161/01. cir.72.6.1257)

54 O'Rourke MF, Adji A \& Safar ME. Structure and function of systemic arteries: reflections on the arterial pulse. American Journal of Hypertension 201831 934-940. (https://doi.org/10.1093/ajh/hpy084)

55 Wilenius M, Tikkakoski AJ, Tahvanainen AM, Haring A, Koskela J, Huhtala H, Kähönen M, Kööbi T, Mustonen JT \& Pörsti IH. Central wave reflection is associated with peripheral arterial resistance in addition to arterial stiffness in subjects without antihypertensive medication. BMC Cardiovascular Disorders 201616 131. (https://doi. org/10.1186/s12872-016-0303-6)

56 Vlachopoulos C, Aznaouridis K, O’Rourke MF, Safar ME, Baou K $\&$ Stefanadis C. Prediction of cardiovascular events and all-cause mortality with central haemodynamics: a systematic review and meta-analysis. European Heart Journal 201031 1865-1871. (https:// doi.org/10.1093/eurheartj/ehq024) 
57 Smith JC, Page MD, John R, Wheeler MH, Cockcroft JR, Scanlon MF \& Davies JS. Augmentation of central arterial pressure in mild primary hyperparathyroidism. Journal of Clinical Endocrinology and Metabolism 200085 3515-3519. (https://doi.org/10.1210/jcem.85.10.6880)

58 Kelly RP, Millasseau SC, Ritter JM \& Chowienczyk PJ. Vasoactive drugs influence aortic augmentation index independently of pulsewave velocity in healthy men. Hypertension 200137 1429-1433. (https://doi.org/10.1161/01.hyp.37.6.1429)

59 McEniery CM, Wallace S, Mackenzie IS, McDonnell B, Yasmin, Newby DE, Cockcroft JR \& Wilkinson IB. Endothelial function is associated with pulse pressure, pulse wave velocity, and augmentation index in healthy humans. Hypertension 2006 48 602-608. (https://doi.org/10.1161/01.HYP.0000239206. $64270.5 f)$

60 Bansal N, Zelnick L, Robinson-Cohen C, Hoofnagle AN, Ix JH, Lima JA, Shoben AB, Peralta CA, Siscovick DS, Kestenbaum B, et al. Serum parathyroid hormone and 25-hydroxyvitamin D concentrations and risk of incident heart failure: the Multi-Ethnic Study of Atherosclerosis. Journal of the American Heart Association 20143 e001278. (https://doi.org/10.1161/JAHA.114.001278)

Received in final form 17 November 2020

Accepted 3 December 2020

Accepted Manuscript published online 8 December 2020 (c) 2021 The authors Published by Bioscientifica Ltd
This work is licensed under a Creative Commons Attribution-NonCommercial-NoDerivatives 4.0 Internationad dicense ifica. com at 04/26/2023 12:21:26PM 